\title{
Applying Program Theory-Driven Evaluation to Design, Implement and Evaluate Geography Learning Community Program — Case Study
}

\author{
Su-ching Lin \\ National Changhua University of Education, Taiwan \\ E-mail:sclin@cc.ncue.edu.tw \\ Ming-sui Wu \\ Ming-Chuan University, Taiwan \\ E-mail: mswu@mail.mcu.edu.tw
}

Yi-Ling Chen

Chu-Tang Junior High School, Taiwan

E-mail: vanity-snow@hotmail.com

Received: February 19, 2017 Accepted: March 20, 2017 Published: March 22, 2017

doi: 10.5296/jsss.v4i2.10787 URL: http://doi.org/10.5296/jsss.v4i2.10787

\begin{abstract}
This study aimed to apply program theory-driven evaluation to design, implement, and evaluate Geography Learning Community Program ( GLCP) and focused on investigating the impacts of GLCP on students' communicative capability, learning attitude, and critical thinking ability. Program theory in this study was based on philosophy of Learning Community advocated by Manabu Sato, Japanese Scholar. The participants consisted of 25 eight-grade students. Based on eighth grade Geography textbook, the authors cooperatively designed 4 unit teaching materials, and implemented them for 12 weeks. During the research period, the data were collected through teaching reflection journals, classroom observations, student worksheets, student learning reflections, semi-structured interviews, communicative capability survey, learning attitude survey, and critical thinking survey. Data analyses
\end{abstract}




\section{$\triangle$ Macrothink}

included both qualitative and quantitative methods. Both the analyses of quantitative and qualitative data indicated that GLCP could promote student's interpersonal relationships, learning attitudes, and students' critical thinking abilities.

Keywords: Critical thinking, Learning attitude, Learning community, Communicative capability, Program theory-driven evaluation

\section{Introduction}

For a long time, the junior high school education in Taiwan has been impacted by entrance examinations, junior high schoolers have to stay in school late to do more practices including a lot of repeating, reciting, and memorizing learning, which make them lack learning motivations. Peers' interaction, exploratory, corporative and reflective learnings in the class are also limited (Pan, 2013). Therefore, if the Taiwanese junior high schools would want to promote students' learning motivation, peers' interaction, and critical thinking ability, it is necessary to change current schooling educational practices. Geography subject in schooling has been regarded as one of important subjects in the schooling. Students would learn patience, carefulness, logical reasoning, and problem resolution from this subject. However, to most of junior high school students, Geography is the boring subject to learn. How to make this subject more interesting to learn is very important to teachers.

More than three decades ago, Manabu Sato, Japanese Scholar, observed schooling phenomenon: schools' assessment system encouraged individual competition and test scores; teachers' teaching emphasized on memorizing instead of practicing; students were isolated and didn't have much interaction with peers in learning activities. Besides, the students didn't understand the meaning and values of the learning and lost the learning motivation and interests, some, even, gave up studies (Sato, 2013; Huang, 2013). In order to overcome the crisis of the students' "escape from learning", Sato has advocated applying the Learning Community (LC) approach in school settings, which created dramatic changes in the Japanese fundamental education. LC is a paradigm shift for teaching and learning. While traditional paradigm focuses on how teachers teach, LC puts more attention to how students learn (Sato, 2012). Based on Sato' opinion, learning should be a sustainable process of constantly weaving the relationship and the meanings. Therefore, Sato claimed, it is very important for students to have dialogues with learning materials, with peers, and with themselves to promote continuous meaningful learning. The role of teacher is to provide guidance to students so they would improve the learning qualities in sharing experiences, dialectics, and connections of their lives (Sato, 2012). Along with the long period of implementing LC, students could enhance their learning capabilities, enjoyed learning, and reached higher academic achievement (Sato, 2013; Huang, 2011). Several related research in Taiwan indicated using LC teaching strategies in reading class could promote students' critical thinking ( Hsu, 2013), learning motivation and reading comprehension (Chen \& Shi, 2014; Chen, 2013), and peer's interaction (Syue, 2013). If Manabu Sato's LC teaching strategy could improve the phenomenon of students' giving up learning in Japan, is it suitable to be applied in Taiwan? If LC teaching strategies could promote students' critical thinking, learning motivation, and peer's interaction in reading class, could it also enhance students' 
critical thinking, learning motivation, and peer's interaction in the Geography class?

Program evaluation in the past has been studied from various angles, including "method-driven," "black box," and "input/output." Program theory-driven evaluation (PTDE) provides a reasonable alternative to these traditional method-driven approaches that have come up somewhat short in evaluation (Donaldson, 2003). One of the advocators of PTDE, Peter Rossi, described PTDE as "the systematic application of social research procedures in assessing the conceptualization, design, implementation, and utility of social intervention programs" (Rossi \& Freeman, 1985, p. 19). PTDE approach can be regarded as a particular type of comprehensive evaluation which involves the construction of a detailed program theory that is used to guide the evaluation (Christie \& Alkin, 2012).

Chen (1990) presented two kinds of PT, nomative theory and causal theory. Nomative theory provides guidance on what goals and outcomes should be pursued or examined, whereas causal theory deals with how the program works. Guided by PT conceptual framework, PTDE approach provides a holistic assessment of a program and rich information about how and why a program succeeds or fails in reaching its program goals. This information is very useful to stakeholders in meeting their program accountability and ongoing needs (Chen, 2006). This approach to evaluation practice has become quite popular and now provides a foundation for some of the most widely used textbooks on program evaluation (Donaldson, 2003). As Rosas (2005) said, PTDE enhances program conceptualization and implementation, improves evaluation design sensitivity, facilitates evaluation use, and creates value for stakeholders.

Based on the above, the current study adopted Manabu Sato's LC teaching strategy to teach Geography subject in a junior high school class. Moreover, the current study applied PTDE to design, implement, and evaluate Geography Learning Community Program (GLCP) and focused on investigating the impacts of GLCP on students' communicative capability, learning attitude, and critical thinking ability. Thus, this study was to investigate the following research questions:

1) Do students improve communicative capability after attending GLCP?

2) Do students enhance learning attitude after attending GLCP?

3) Do students increase critical thinking ability after attending GLCP?

\section{Methodology}

The participants in this study consisted of 25 eight-grade students. Based on eight grade textbook, the authors cooperatively designed 4 unit teaching materials and implemented them for 12 weeks. During the research period, the data were collected through teaching reflection journals, classroom observations, student's worksheets, semi-structured interviews, communicative capability survey, learning attitude survey, and critical thinking survey. Data analyses included both qualitative and quantitative methods. The research procedure in the current study was comprised of: 1) constructing logical model of GLCP framework; 2) designing GLCP; 3) implementing and evaluating GLCP, which were described in detail in 


\section{Macrothink}

the next following paragraphs.

\subsection{Constructing Logical Model of GLCP Framework}

First, the authors developed constructing logical model of GLCP framework program theory, which consisted of the following elements, such as principles, sources, components, activities, factors and expected outputs (shown as Figure 1). The details were as follows:

1) GLCP principles: The core concepts of curriculum design include the dialogue with teaching materials, the dialogue with the peers, and the dialogue with oneself.

2) GLCP components: GLCP components majorly include three kinds of learning activities, learning by doing, collaborative learning, and reflective learning. Learning by doing refers to activities of exploration, explanation, induction, assumption, verification, and knowledge construction. Collaborative Learning refers to grouping students. Each group learns to listen to each other, to discuss with peers, and to construct knowledge during peer' sharing their opinions aside from cooperating with peers during doing individual assignments and extensive learning. Reflective learning refers to activities of questioning the teaching materials, reflecting on the processes of learning experiences, and clarifying confusing concepts.

3) GLCP activities: GLCP activities include lesson previews, experimental operation, discussions, filling out the worksheets, providing reflection and feedback, and learning notes.

4) GLCP outputs: The expected outputs include enhancing learning attitudes, improving interpersonal relationships, and critical thinking skills.

5) External factors: The potential external factors may include experimental units and content, teachers' professional ability, teaching time and resources, resource allocation, assessment methods and tools, and parents attitude, etc.

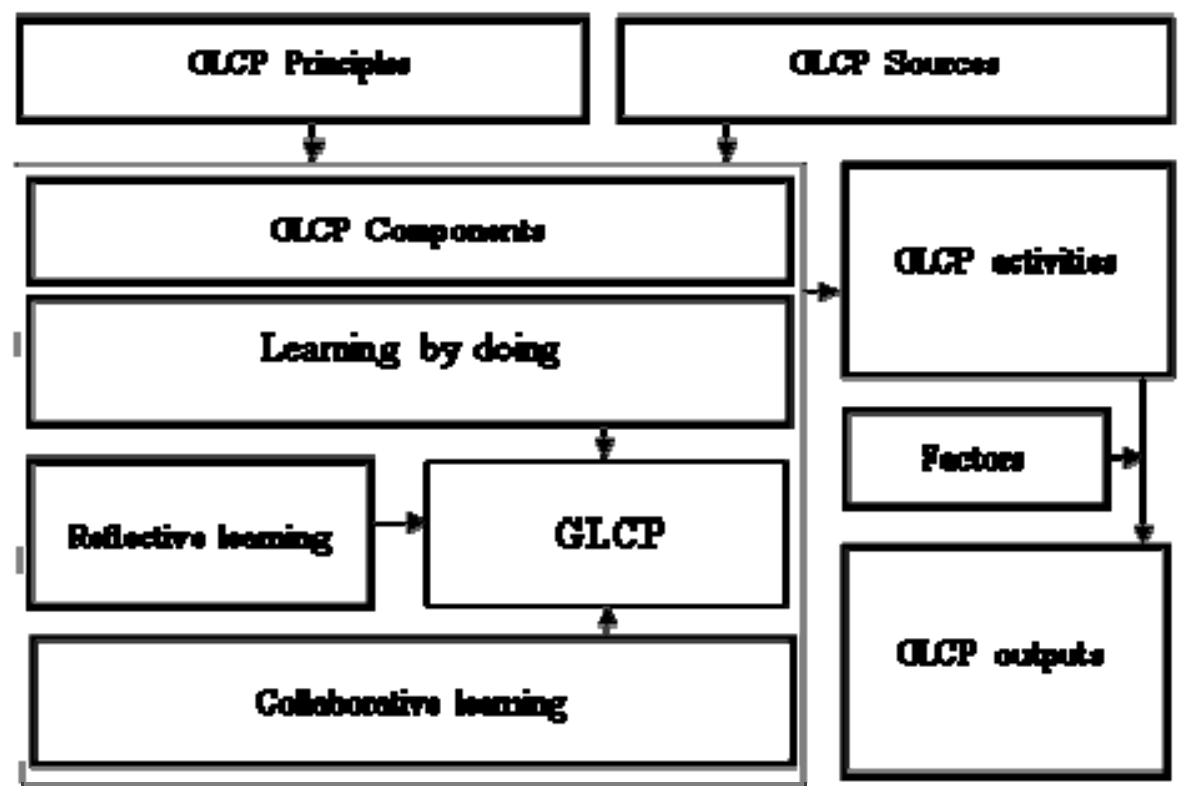

Figure 1. Logical model of GLCP framework 


\subsection{Designing GLCP and Developing Instruments}

Based on logical model of GLCP framework and contents of eight grade textbook, the authors designed GLCP, which consisted of 4 units including "development of the area of south of China", "development of the area of north of China", "development of the area of west of China", and "world geography overview". Each unit was taught for 3 weeks and 45 minute per week. Learning activities of GLCP majorly included learning by doing, collaborative learning, and reflective learning. Every student was asked to preview each lesson before class begin, to attend experimental operation and discuss among the peers during the class, and to fill out the worksheets(such as lesson feedback sheets, activity records) after class.

Three research instruments were developed in this study. The first research instrument, Communicative Capability Survey (CCS) was developed. Sixteen items in CCS were designed to measure five dimensions including empathy, expression, listening, self-disclosure, and peer-interaction. Students were asked to rate the items on a five-point Likert scale anchoring at 1, 2, 3, 4, and 5 ( from strongly disagree to strongly agree). The factor analysis made on data obtained by CCS in the current application reveals that each item in all subscale dimensions produced factor loadings was.73. The overall internal consistency (Cronbach's $\alpha$ $=.86$ ) for the scale in the current sample was good. The Cronbach's $\alpha$ for the three subscales ranged from .72 to .86 , indicating good internal consistencies of the items within each subscale.

The second research instrument, Learning Attitude Survey (LAS) was developed. Twenty-two items in LAS were designed to measure five dimensions of toward one's self, curriculum, instructor, classmates, and learning resources. Students were asked to rate the items on a five-point Likert scale anchoring at 1,2, 3, 4, and 5 ( from strongly disagree to strongly agree). The factor analysis made on data obtained by LAS in the current application reveals that each item in all subscale dimensions produced factor loadings was.64. The overall internal consistency (Cronbach's $\alpha=.90$ ) for the scale in the current sample was good. The Cronbach's $\alpha$ for the three subscales ranged from .75 to .86, indicating good internal consistencies of the items within each subscale.

The third research instrument, Critical Thinking Survey (CTS) was developed. Twenty items in CTS were designed to measure five dimensions including six dimensions of logical thinking, analytic ability, open-mindedness, curiosity of intellectual, and reflective thinking. Students were asked to rate the items on a five-point Likert scale anchoring at 1, 2, 3, 4, and 5 ( from strongly disagree to strongly agree). The factor analysis made on data obtained by LAS in the current application reveals that each item in all subscale dimensions produced factor loadings was.42. The overall internal consistency (Cronbach's $\alpha=.88$ ) for the scale in the current sample was good. The Cronbach's $\alpha$ for the three subscales ranged from .58 to .83 , indicating good internal consistencies of the items within each subscale.

\subsection{Implementing and Evaluating GLCP}

The current study adopted Manabu Sato's LC approach to teach Geography subject in a 
junior high school class and applied PTDE to design, implement, and evaluate GLCP. During the period of program implementation, the authors based on evaluation questions applied several tools to collect data in order to assess outcomes and impacts of the program. However, the current study only focused on presenting the impacts of GLCP on students' communicative capability, learning attitude, and critical thinking ability in this paper.

\section{Findings}

\subsection{The Influences of GLCP on Students ' Communicative Capability}

Table 1 showed difference analysis results, which indicated that significant differences between pre-test scores and post-test scores in communicative capability survey, including dimensions of empathy $(t=-10.53, p<.001)$, expression $(t=-12.96, p<.001)$, listening $(t=-11.80$, $p<.001)$, self-disclosure $(t=-9.88, p<.001)$, peer-interaction $(t=-9.29, p<.001)$, and overall $(t=-19.13, p<.001)$. Significant results indicated that post-test had higher scores on dimensions of communicative capabilities and overall than that of pre-test.

Table 1. $t$-test of dimensions of communicative capability survey

\begin{tabular}{llllll}
\hline \multirow{2}{*}{ Dimensions } & $\begin{array}{c}\text { Pre-test } \\
(N=25)\end{array}$ & $\mathrm{M}$ & $\begin{array}{c}\text { Post-test } \\
(N=25)\end{array}$ & \multicolumn{1}{c}{$t$} \\
\cline { 2 - 5 } empathy & 3.49 & 1.16 & 4.53 & 0.41 & $-10.53^{* * *}$ \\
expression & 2.95 & 0.61 & 4.32 & 0.39 & $-12.96^{* * *}$ \\
listening & 3.11 & 0.38 & 4.33 & 0.37 & $-11.80^{* * *}$ \\
self-disclosure & 3.24 & 0.60 & 4.48 & 0.32 & $-9.88^{* * *}$ \\
peer-interaction & 2.99 & 0.54 & 4.04 & 0.48 & $-9.29 * * *$ \\
\hline overall & 3.15 & 0.38 & 4.34 & 0.30 & $-19.13 * * *$ \\
\hline
\end{tabular}

$* * * p<.001$.

The qualitative data analysis also showed that most of students were affected by GLCP. First, students learned how to respect, share, and express. Due to team grouping, students were sitting together, which was helpful to create discussion climate for students. In the ongoing class activities, they started learning how to share and express their own opinions and tried to make a connection and inductions between what they learned and what they discussed. Most of the students provided very positive feedback on how GLCP impacted them on learning to share, respect and express. For examples:

I was more willing to discuss with the classmates initiatively when I had questions because we sat together. (160503 Sho Da's lesson feedback sheets)

We had more interaction when we communicated with the teammates than when we only had the instructor's lecture in the class. (160507 Sho Chuan's lesson feedback sheets) 


\section{Macrothink

I enjoyed in the Geography class much more now because I could discuss with the classmates. Also, I would not understand what people were discussing if I didn't pay enough attention in the class. (160511 the interview with Sho Chuan)

Second, students learned how to mutual tolerance and cooperation with the teammates. Random grouping challenged the students' capabilities to get along with people; most of them were doing well and cooperative. They were able to cooperatively make an effort to get the honors when they had any challenges. Students who were lower academic achievement would still like to give a try and ask questions. Students who had higher academic achievement were also willing to help classmates and accepted the various responses from the others. Some of them shared their experiences as follows:

Actually, I didn't like to speak up because I seldom provided the correct answers. But it required us to discuss together in the class activities to get the scores. Therefore, I started trying to provide my own opinion. Surprisingly the teammates respected and tolerated me. They showed their appreciation to me when I got the answers correct. (160519 the interview with Sho Ling)

In the class activity entitled "World Overview: Climate", all members in each group were working very hard to read the textbooks and the reference books borrowed from the library, and made World Climate Map together. all participated the works. (160504 classroom observation)

The students in Group \#3 were getting much better in the classes recently. They were all keen on the discussions and gained more scores for the team. (160505 classroom observation)

Bases on above qualitative and quantitative analyses, this study confirmed that GLCP provided remarkable positive influences on students' empathy, expression, listening, self-disclosure, and peer-interactions in the case study.

\subsection{The Influences of GLCP on the Students'Learning Attitudes}

Table 2 showed difference analysis results, which indicated that significant differences between pre-test scores and post-test scores in learning attitude survey, including dimensions of toward one's self $(t=-14.45, p<.001)$, curriculum $(t=-11.33, p<.001)$, instructor $(t=-10.27$, $p<.001)$, classmates $(t=-6.83, p<.001)$, learning resources $(t=-6.75, p<.001)$, and overall $(t=-15.55, p<.001)$. Significant results indicated that post-test had higher scores on dimensions of learning attitudes and overall than its counterpart. 
Table 2. t-tests of dimensions of learning attitude survey

\begin{tabular}{|c|c|c|c|c|c|}
\hline \multirow[b]{2}{*}{ Dimensions } & \multicolumn{2}{|c|}{$\begin{array}{l}\text { Pre-test } \\
(N=25)\end{array}$} & \multicolumn{2}{|c|}{$\begin{array}{l}\text { Post-test } \\
(N=25)\end{array}$} & \multirow[b]{2}{*}{$t$} \\
\hline & M & SD & M & SD & \\
\hline One's self & 2.93 & 0.38 & 4.01 & 0.34 & $-14.45 * * *$ \\
\hline curriculum & 2.63 & 0.36 & 4.11 & 0.51 & $-11.33 * * *$ \\
\hline instructor & 3.03 & 0.26 & 4.11 & 0.53 & $-10.27 * * *$ \\
\hline classmates & 3.12 & 0.43 & 4.03 & 0.57 & $-6.83 * * *$ \\
\hline learning resources & 3.14 & 0.45 & 3.90 & 0.46 & $-6.75 * * *$ \\
\hline overall & 2.98 & 0.23 & 4.02 & 0.34 & $-15.55 * * *$ \\
\hline
\end{tabular}

$* * * p<.001$.

The qualitative data analysis also showed that most of students were affected by GLCP. First, students' self-learning attitude got toward positivity. Those students who used to be quiet in the class and seldom participated in the discussion were getting more active after attending GLCP. As some of them shared:

I could feel myself concentrated on the class much better because the classmates would remind me of paying attention. (160511 Sho Gi's activity records)

Honestly to say, I didn't like Geography very much before but I involved myself in class discussion more often now. (160516 Sho Shin's lesson feedback sheets)

I would initiatively answer the questions to gain the scores and I spoke seriously; otherwise, I felt embarrassed. Therefore, I usually did my homework earlier and prepared the classes. I would search the internet if I had any questions. (160514 Sho Chen's activity records)

Moreover, some of students paid more attention on other geographic issues in the daily life after they learned the relevant geographical concepts in the class. As Sho Yan said:

After the "World Overview: Climate" activity, I was not against reading map any more. I would try to read the maps on other subjects when I saw those now. (160511 Sho Yan's activity records)

Second, students enjoyed the Geography class and learning style, collaborative learning, which was different from traditional teacher-centered instruction, so it raised the students' learning motivation and make learning more fun in the class. Some students provided very positive feedbacks on enjoying the Geography classes and teaching style. For examples:

I was interested in Geography because of those amusing activities in the classes. (160506 Sho Ming's weekly learning notes)

It raised my interest in learning Geography through the various learning activities and some of games. Also I concentrated my attention in the class in order to get a better score in the competition. (160513 the interview with Sho Zhen) 


\section{Macrothink Institute ${ }^{\text {TM }}$}

I preferred collaborative learning in which I was able to pay more attention in the team. (160515 Sho Yin's lesson feedback sheets)

It was not boring anymore in Geography class because I could discuss with my classmates. (160517 the interview with Sho Yu)

I listened more carefully in Geography class because it required the team works. (160518 the interview with Sho Hang)

During classroom observation, the authors also discovered that students more involved themselves in learning.

I was able to tell from their eyes and faces that those students were fully concentrated in the team contest. (160509 classroom observation)

Usually, the children felt they participated more in the collaborative teaching. (160413 classroom observation)

Third, teachers and students or peers were getting closer psychologically. Collaborative learning provided students' sense of security and trust in the learning environment which was helpful to get the instructor and their students closer. The instructor shared her teaching reflection journals as follows:

I felt so happy because some students came to my office actively to help me carry the textbooks and equipment before the class began. (160329 teaching reflection journal)

Sho Gi thanked to me after the class; besides that he really liked the "Little Live Reporter" activity, but also he appreciated that teachers and team members patiently listened to him even though he was stammering in the presentation. (160329 teaching reflection journal)

The relationship between students and me was getting closer. They smiled to me and initiatively greeted me. (160503 teaching reflection journal)

In addition, some students shared their learning experiences in Geography class, for examples:

It was a lot fun in the Geography class because I could learn with my classmates together. (160523 Sho Zong's activity records)

I was able to be more concentrated and involved in the class because I had the sense of participation. (160525 Sho Shue's lesson feedback sheets)

It was great to discuss with people because I had teammates. (160524 Sho Yi's lesson feedback sheets)

Fourth, some students utilized library or internet resources to enhance their knowledge of Geography in order to get better team score in the class activities or simply motivated by the enthusiasm in Geography class. Some of them shared their experiences. For examples:

Our team borrowed books from the library in order to answer the questions promptly in the last few weeks. (160504 Sho Shing's lesson feedback sheets)

I really enjoyed the "World Overview: Nations" activity. I learned about some characteristics of several famous countries in the world through the event. Sho Zong and I 
also went to the library to search for the introduction of other countries. (160511 Sho Chen's lesson feedback sheets)

Based on the above analyses, this study confirmed that the GLCP provided remarkable positive influences on students' attitudes to themselves, curriculum, the instructor, classmates and using learning resources in the case study.

\subsection{The Influences of GLCP on the Students' Capabilities of Critical Thinking}

Table 3 showed difference analysis results, which indicated that significant differences between pre-test and post-test in critical thinking survey, including six dimensions of logical thinking $(t=-2.88, p<.01)$, analytic ability $(t=-3.90, p<.001)$, open-mindedness $(t=-5.77, p$ $<.001)$, curiosity of intellectual $(t=-2.66, p<.01)$, reflective thinking $(t=-2.50, p<.01)$, and overall $(t=-3.71, p<.001)$. Significant results indicated post-test had higher scores on dimensions of learning attitudes and overall than that of pre-test.

Table 3. t-tests of dimensions of critical thinking survey

\begin{tabular}{llllll}
\hline & $\begin{array}{l}\text { Pre-test } \\
(N=25)\end{array}$ & \multicolumn{3}{l}{$\begin{array}{l}\text { Post-test } \\
(N=25)\end{array}$} \\
\cline { 2 - 5 } Dimensions & $\mathrm{M}$ & $\mathrm{SD}$ & $\mathrm{M}$ & $\mathrm{SD}$ & \multirow{2}{*}{$t$} \\
\hline logical thinking & 3.00 & 0.44 & 3.37 & 0.86 & $-2.88^{* *}$ \\
analytic ability & 2.99 & 0.41 & 3.45 & 0.74 & $-3.90^{* * *}$ \\
open-mindedness & 3.23 & 0.33 & 3.88 & 0.69 & $-5.77^{* * *}$ \\
curiosity of intellectual & 3.09 & 0.51 & 3.37 & 0.80 & $-2.66^{* *}$ \\
reflective thinking & 3.05 & 0.55 & 3.39 & 0.93 & $-2.50^{* *}$ \\
\hline overall & 3.04 & 0.36 & 3.44 & 0.78 & $-3.71^{* * *}$ \\
\hline
\end{tabular}

$* * p<.01 . * * * p<.001$.

The qualitative data analysis also showed that most of students were able to constantly enhance their logical expression, open-minded learning and sharing, curiosity of intellectual, reflective thinking, which were described in the next following paragraphs.

First, students presented their opinions logically. In the second half of the current study, the instructor found that most of the students were able to talk about the subjects easily and presented their opinions logically. As she said:

I was able to discover that students could provide more organized presentations; most of them were able to talk confidently. (160524 classroom observation)

Moreover, some of students shared their experiences in presentation as follows: 
I was not that nervous as before because team work provided me more opportunities to have presentations and speeches. (160513 Sho Zhen's lesson feedback sheets)

I would think of the orders in my mind before the presentations. My capabilities of expression were getting improved. (160521 Sho Yee's lesson feedback sheets)

It seemed my expression was getting a lot better after the several presentations in the classes. (160524 the interview with Sho Yi)

Second, students were able to cooperate and learn together under the comfortable environment. They were also open-minded to accept the opinions from all teams and enjoy the diversities. As they said:

As long as someone would like to help you, any issues could be resolved. My teammates were all very zealous; they were willing to provide their assistances on a lot of difficult issues. (160504 the interview with Sho Yan)

Everyone would learn together in the discussion; we learned the new knowledge by sharing the experiences. (160515 the interview with Sho Yin)

I was able to resolve my own questions in my group and help other teammates who had problems. (160522 Sho Shing's lesson feedback sheets)

Third, students kept the curiosity to pursue new knowledge in the class. It could only ignite the enthusiasm of learning in the short class time; students started to have endless eager on the pursuit of knowledge. Some of them would use their spare time to search for the extra information to broaden horizons after discussions in the class. As they said:

I would look for the information in the library myself if I was curious on something discussed in the class. (160509 Sho Wei's lesson feedback sheets)

Sometimes I would browse websites at home to search for what I learned in the class because I would like to learn more and to understand thoroughly. (160525 Sho Shue's lesson feedback sheets)

Fourth, students constantly reflected on self-learning process. Each group conducted self-assessment on learning processes weekly in the end of each stage of curricular activities. Most of them were able to review and modify self-learning process. As they said:

Thanks for Sho Zhen's help. I hope I could be more valiant when I answer the questions. (160506 Sho Ming's lesson feedback sheets)

I should have initiatively researched and prepared more data in order to provide the correct answers for the questions. (160507 Sho Chi's lesson feedback sheets)

Based on the above analyses, this study confirmed that the GLCP provided remarkable positive influences on logical thinking, analytic ability, open-mindedness, curiosity of intellectual and reflective thinking in the case study.

\section{Discussions and Conclusions}

This study aimed to apply program theory-driven evaluation to design, implement, and evaluate Geography Learning Community Program (GLCP) and focused on investigating the 
impacts of GLCP on students' communicative capability, learning attitude, and critical thinking. Three findings were found in this study. First, GLCP provided remarkable positive influences on students' communicative capability such as the students' similarity responses, expression, listening, self-disclosure and social interactions in the case study. This finding resembles that of Sato (2013) to some extent also support claims of Syue (2013), in that LC is believed to be capable of helping students to increase peer's interaction. One of the reasons for increasing GLCP students' communicative capacity is probably that due to team grouping, students were sitting together and were asked to finish learning tasks collaboratively, which benefited to create interaction environment for students. Second, GLCP made significant positive influences on students' learning attitude such as the students' attitudes to themselves, classes, instructors, classmates and learning resources in the case study. This finding is similar to that of Chen and Shi (2014) to some extent also support claims of Chen (2013), in that LC is believed to be capable of helping students to enhance learning attitude. One of the reasons for improving GLCP students' learning attitude is probably that because of students enjoying learning styles which was different from traditional teacher-centered instruction, so GLCP raised the students' learning motivation and make learning more fun in the class. Third, GLCP provided significant positive influences students' critical thinking such as systemic analysis, open-mindedness, curiosity of intellectual and reflection thinking. This finding resembles that of Hsu (2013) to some extent also support claims of Sato (2013), in that LC is believed to be capable of helping students to increase critical thinking ability. One of the reasons for improving GLCP students' critical thinking ability is probably that because of students being open-minded to accept the opinions from all teams and enjoy the diversities. Moreover, students used their spare time to search for the extra information to broaden horizons after discussions during attending GLCP.

To sum up, students improved their communicative capability, learning attitude, and critical thinking ability after GLCP because LC teaching strategy, which stressed learning by doing, collaborative learning, and reflective learning could make students enjoy learning processes and reflecting their own learning progress which was different from traditional teacher-centered instruction.

\section{Acknowledgement}

The authors would like to thank the Ministry of Science and Technology, Taiwan for financially supporting this research under Contract No. MOST 105-2410-H-018 -017-MY2

\section{References}

Chen, H. T. (1990b). Theory-driven evaluations. Newbury-Park, CA: Sage.

Chen, H. T. (2006). A theory-driven evaluation perspective on mixed methods research. Research in the Schools, 13(1), 75-83.

Chen, M. L., \& Shi, H. S. (2014). Combined with the concept of Mind Mapping and Learning Community to student's reading course. Taiwan Education Review Monthly, 3(6), 31-36.

Chen, X. X. (2013). Handbook of textbook-based reading comprehension instruction. Taipei, 


\section{Macrothink}

Taiwan: Ministry of Education.

Christie, C. A., \& Alkin, M. C. (2012). An evaluation theory tree. In M. C. Alkin (Ed.), Evaluation Roots ( $2^{\text {nd }}$ Ed). Thousand Oaks, CA: Sage.

Donaldson, S. I. (2003). Theory-Driven Program Evaluation in the New Millennium. In S. I. Donaldson, \& M. Scriven (Eds.), Evaluating social programs and problems: Visions for the new Millennium(pp.109-141). New Jersey: Lawrence Erlbaum.

Hsu, Y. C. (2013). When Text-based Reading Comprehension Instruction encounter Learning Community. Taiwan Education Review Monthly, 2(9), 38-41.

Huang, Y. L. (2011). Inspire the joy of learning and potential - The Introduction and implementation of learning community in Japanese Education Reform. The Educator monthly, $171,39-42$.

Huang, Z. J. (2013). Learning Community is surging. The Educator monthly, 552, 1-4.

Pan, H. L. (2013). Reform horn sounded, creating a different class landscape. In C. Wealth (Ed.), Learning community -First time experience (pp. 78-87). Taipei, Taiwan: Common Wealth.

Rosas, S. R. (2005). Concept mapping as a technique for program theory development: An illustration using family support programs. American Journal of Evaluation, 26, 389-401. https://doi.org/10.1177/1098214005278760

Rossi, P. H., \& Freeman, H. E. (1985). Evaluation: a systematic approach (3 ${ }^{\text {rd }}$ ed.). Beverly Hills, CA: Sage. https://doi.org/10.1177/0193841X8500900601

Sato, M. (2012). Learning Revolution: starting from the classroom reform. Taipei, Taiwan: Tian-Xia Magazine.

Sato, M. (2013). The Learning community: Constructs and praxis. Taipei, Taiwan: Tian-Xia Magazine.

Syue, Y. C. (2014). The research on Learning Community to start a new study patterns from junior high school's teacher. Journal of Research in Education Sciences, 59(1), 101-140.

\section{Copyright Disclaimer}

Copyright for this article is retained by the author(s), with first publication rights granted to the journal.

This is an open-access article distributed under the terms and conditions of the Creative Commons Attribution license (http://creativecommons.org/licenses/by/3.0/). 